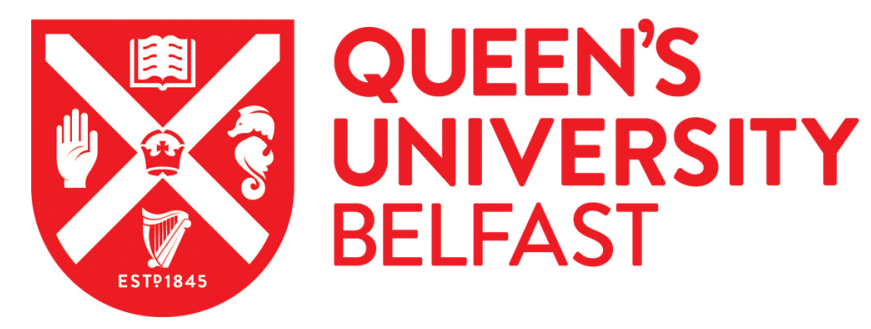

\title{
Wholegrains and health: Many benefits but do contaminants pose any risk?
}

Nugent, A. P., \& Thielecke, F. (2019). Wholegrains and health: Many benefits but do contaminants pose any risk? Nutrition Bulletin, 44(2), 107-115. https://doi.org/10.1111/nbu.12379

\section{Published in:}

Nutrition Bulletin

\section{Document Version:}

Peer reviewed version

\section{Queen's University Belfast - Research Portal:}

Link to publication record in Queen's University Belfast Research Portal

\section{Publisher rights}

Copyright 2019 Wiley. This work is made available online in accordance with the publisher's policies. Please refer to any applicable terms of use of the publisher.

\section{General rights}

Copyright for the publications made accessible via the Queen's University Belfast Research Portal is retained by the author(s) and / or other copyright owners and it is a condition of accessing these publications that users recognise and abide by the legal requirements associated with these rights.

Take down policy

The Research Portal is Queen's institutional repository that provides access to Queen's research output. Every effort has been made to ensure that content in the Research Portal does not infringe any person's rights, or applicable UK laws. If you discover content in the Research Portal that you believe breaches copyright or violates any law, please contact openaccess@qub.ac.uk. 
Wholegrains and health: many benefits but do contaminants pose any risk?

A. P. Nugent ${ }^{*}$ and F. Thielecke ${ }^{+}$

*Queens University Belfast, Northern Ireland \& University College Dublin, Ireland

${ }^{+}$Swiss Distance University of Applied Sciences, Regendorf-Zurich, Switzerland

Correspondence: Dr. Anne Nugent, Senior Lecturer, Institute for Global Food Security, School of Biological Sciences, Queens University Belfast, Northern Ireland BT9 5HN. Institute of Food and Health, University College Dublin, Dublin, Ireland. Email: a.nugent@qub.ac.uk

Running title: The safety of wholegrains in our diet

Key Words: wholegrain; contaminant; mycotoxin; heavy metal; health 


\section{Abstract}

Since prehistoric times, humans have consumed grains as part of their diet. Being rich in carbohydrates, grains typically form a key part of all food-based dietary guidelines, with wholegrains recommended as healthy dietary choices. However, grains are also naturally exposed to contaminants and can be one of the main dietary sources of food borne contaminants by virtue of their frequent consumption. Recent scientific reports positively highlight wholegrains as foods with inherent health properties, which, because they provide fibre and micronutrients such as B vitamins and zinc, can improve the quality of carbohydrate intake as part of sustainable healthy diets. This article describes potential protective properties inherent to wholegrains and contends that the presence of contaminants in wholegrains merits continued monitoring but that any such risk does not outweigh the known benefits of wholegrain consumption.

Key Words: wholegrain; contaminant; mycotoxin; dietary exposure; fibre; health What are grains and wholegrains?

Cereal grains are food staples and represent the primary carbohydrate source in the human diet worldwide. Today, three grains (rice, maize and wheat) provide about $60 \%$ of the world's food energy (FAO 2018a), with the Food and Agriculture Organization (FAO) forecasting that world grain utilisation in 2018/2019 will reach a record level of 2646 million tonnes (FAO 2018b). For wholegrains specifically, several definitions have been suggested (Van der Kamp et al. 2014; AACC International, 2018), all of which principally agree that: 'wholegrains consist of the intact, ground, cracked or flaked caryopsis (kernel) after the removal of inedible parts such as the hull and husk. The principal anatomical components-the starchy endosperm, germ and bran-are present in the same relative proportions as they exist in the intact kernel'. The definition by the Healthgrain Forum acknowledges that some parts of the grain, such as the outermost layers, are removed during processing to eliminate potential contamination of the outer bran (Van der Kamp et al. 2014).

The most commonly consumed wholegrains in Western Europe are wheat, oats, rye and barley, with wholegrain products including porridge, breakfast cereals, breads, whole wheat pasta and snacks such as oatcakes, popcorn and wholegrain cereal bars (BDA 2016; CPW 2017). Compositionally, wholegrains are nutrient dense providing fibre as well as $B$ vitamins, vitamin $E$, magnesium, zinc, iron, copper, selenium and other bioactive compounds (EUFIC 2015; BDA 2016). Nevertheless, dietary intakes of wholegrains are typically low, with $18 \%$ of UK adults and $15 \%$ of UK children and adolescents not consuming any wholegrains in the most recent analysis of wholegrain intakes in the National Diet and Nutrition Survey (2008-2011) and only $17 \%$ of adult and $6 \%$ of children achieving the US dietary 
recommendation of $48 \mathrm{~g} /$ day wholegrain (Mann et al. 2015). This is similar to that reported in other European countries (Bellisle et al. 2014; Sette et al. 2017; O'Donovan et al. 2018), notable exceptions including Denmark where wholegrain intakes have increased to up to $63 \mathrm{~g} /$ day as a results of a multistakeholder, national campaign (Greve \& Ness 2014; Ness et al. 2014). Consumer insights suggest such low intakes may be due to lack of awareness of the benefits of wholegrain and how much should be consumed (CPW, 2017), in addition to negative perceptions in relation to their cost, ease of use and flavour (Kuznesof et al. 2012; McMackin et al. 2013). The latter perhaps routed in the Nineteenthcentury industrialisation when new processing techniques, such as rolling mills, more effectively removed the husks of wheat and rice resulting in 'white flour', which was more popular with consumers. Increasing awareness of the health benefits of wholegrains coupled with growing consumer interest in healthier food products in recent years has resulted in food manufacturers including more wholegrains in cereal products, globally (Seal \& Thielecke 2018)

\section{Health benefits of consuming wholegrains}

High consumption of wholegrains in the human diet has been associated with decreased risk of developing several chronic diseases (Reynolds et al. 2019), such as cardiovascular disease (Wu et al. 2015), type 2 diabetes (Ye et al. 2012) and possibly obesity (Albertson et al. 2016) and cancer (Aune et al. 2011). Although the exact mechanisms by which wholegrains may exert such a protective effect remain to be elucidated, the generation of betainized compounds in vivo following the consumption of wholegrain-rich diets appears to be protective for glucose metabolism at least (Kärkkäinen et al. 2018). Overall, there is a growing body of evidence indicating that people who consume more wholegrains have a lower risk of some chronic diseases compared with people who include few wholegrains in their diet (Wu et al. 2015; Benisi-Kohansal et al. 2016; Zong et al. 2016). The Global Burden of Disease study (2015) estimated that low wholegrain intake resulted in almost 4 million Disability Adjusted Life Years (DALYs) in the European Union (EU) in 2015, and almost 270000 avoidable deaths from all causes (of which 250000 were from cardiovascular disease) (GBD, 2018). The growing evidence base on the health benefits of wholegrains has led governmental authorities and scientific organisations to issue specific recommendations for wholegrains, advising that they are consumed in place of foods that are made from refined grains (Seal et al. 2016; SACN 2015), for example in the UK wholegrains are mentioned as part of food based dietary guidelines but as yet no quantititve guidelines exist (Seal et al. 2015). Practical guidance exists for consumers in the form of on-pack product health claims in the US (FDA 2018) and suggestions for labelling or identifying wholegrain foods including use of logos by expert organisations such as the Healthgrain Forum in Europe (Ross et al. 2017) and the Whole Grains Council in the US (Whole Grain Stamp 2005). 
The mechanisms underlying the health benefits of wholegrains are not fully understood but may relate to their fibre content and its influence on short chain fatty acid production and the gut microbiome, and/or the presence of bioactive compounds (e.g. vitamins, minerals, lignans and phenoilics) (Robinson \& Chambers). Whilst the influence of a food structure/matrix on health outcomes is increasingly recognised for dairy products (Thorning et al. 2017), this is less well characterised for wholegrains (Thielecke \& Nugent 2018).

\section{Contaminants in wholegrains}

While grains are important carbohydrate sources, they naturally contain contaminants and, as a food category, represent one of the main dietary sources of foodborne contaminants (see review by Thielecke \& Nugent, 2018). Food contaminants have been defined as 'any substance not intentionally added to food which is present in such food as a result of the production, manufacture, processing, preparation, treatment, packing, packaging, transport or holding of such food or as a result of environmental contamination' (EC 1993). The potential sources of contaminants in grains are mostly environmental and include air, dust, soil, water, insects, rodents, birds, animals, microbes, humans, storage and shipping containers, and handling and processing equipment. Most contamination is of a microbiological nature but heavy metals and process contamination (e.g. acrylamide) can also occur. Pesticide residues may also be present, with recent sampling reports from the European Food Safety Authority (EFSAsuggesting that any pesticide residues present are well within the limits permitted in EU legislation (EFSA, 2016). Pesticide residues are not discussed further in this article, with the focus on myctoxins, heavy metals and acrylamide.

\section{Mycotoxins}

Mycotoxins are poisonous metabolites produced by certain species of fungi, which can grow on grains. Such fungi may be airborne or soil borne and can infect plants in the field or throughout the production chain (Scudamore \& Patel 2009; Alshannaq \& Yu 2017). Early recordings of poisoning by mycotoxins date back to Assyria in 600 BC (Bennett \& Bentley 1999). Globally, occurrence of mycotoxins in grains remains a significant concern to human health, particularly in developing countries (Lee \& Ryu 2017; Moretti et al. 2017). Five groups of mycotoxins which can affect human health affect grains, namely deoxynivalenol /nivalenol (DON), zearalenone, ochratoxin, fumonisins and aflatoxins. Table 1 lists examples of the grains affected by these mycotoxins and their potential impact on human health. Maize, wheat and barley are primarily affected by all mycotoxins, with adverse effects in humans including nausea and fever, and potentially cancer (Freire \& da Rocha 2016)). 
Levels of mycotoxins tend to be lower in processed foods than wholegrains; however, incidence rates can vary depending on the individual mycotoxin and on selection processes and protocols followed by food manufacturers (Thielecke \& Nugent 2018). Ten-year global occurrence data reveal a consistent presence of mycotoxins in the food supply, with occurrence of samples positive for the individual mycotoxins and the maximum levels in raw grains of $55 \%$ and $1642 \mu \mathrm{g} / \mathrm{kg}$ for aflatoxins, $29 \%$ and 1164 $\mu \mathrm{g} / \mathrm{kg}$ for ochratoxin $\mathrm{A}, 61 \%$ and $71121 \mu \mathrm{g} / \mathrm{kg}$ for fumonisins, $58 \%$ and $41,157 \mu \mathrm{g} / \mathrm{kg}$ for deoxynivalenol, and $46 \%$ and $3049 \mu \mathrm{g} / \mathrm{kg}$ for zearalenone (Lee \& Ryu 2017). Further, while climate change and associated changes in humidity, temperature and water availability is suggested to have a direct influence on presence of mycotoxins, no clear consensus exists. Whilst some climate change modelling indicates no influence on DON contamination of wheat and corn in Europe (Van der FelsKlerx et al. 2013), this is in contrast to other modelling of DON contamination in North Wast Europe (Marvin 2012), and for aflatoxin in maize (Battilani et al. 2016; Moretti et al. 2019) and F. graminearum in Central and North Europe (Moretti et al. 2019).

\section{Metals as contaminants}

Heavy metals such as arsenic, cadmium and lead are naturally found in the earth and most relevant with respect to grain intake (Thielecke \& Nugent 2018). When ingested, such metals can compete with minerals such as calcium, magnesium and iron for absorption but can also bind to cellular components (e.g. structural proteins, enzymes and nucleic acids) disrupting their function (Andrade et al. 2017; Kosek-Hoehne et al. 2017). Chronic exposure to heavy metals leads to wide-ranging health problems affecting the immune system, nervous system and systems relating to reproductive, metabolic and skeletal health (Tchounwou et al. 2012. Grains such as wheat and rice are the major contributors to dietary cadmium intake, while rice contributes to dietary arsenic intake (EFSA 2009, EFSA 2012, EFSA 2014).

The storage sites within grain for cadmium and arsenic are different. Whereas cadmium is primary stored in the endosperm (the endosperm being the main source of white flour) arsenic accumulates mostly in the outer layer of rice. Hence, wholegrain rice with its bran intact can have up to $80 \%$ more arsenic than white rice (Greenerchoices 2019). Nevertheless, rigorous safety assessments by EFSA have concluded that rice is safe to eat by all population groups as part of food-based dietary guidelines, including infants and young children (EFSA 2009; EFSA 2014). Results of ongoing pan-EU monitoring programmes during the period 2017-2018 of the arsenic content of a wide variety of foodstuffs, including grains, will inform the scientific discussion as to whether further safeguards are needed (EC, 2019). 


\section{Acrylamide}

Acrylamide is a chemical that naturally forms in starchy foods when they are cooked at high temperatures such as through roasting, frying or baking, with the general rule of thumb that the browner the food after cooking, the more acrylamide will be present. Grain products, such as bread and breakfast cereals, including wholegrain versions, can also contain acrylamide, level of which will be affected by baking and toasting. . Acrylamide has been classed as potentially carcinogenic (IARC 1994) with the EU Commission updating benchmark values for acrylamide levels in various food categories in 2017 (EC 2017) and proposing levels should be as low as reasonably achievable (ALARA principle).

\section{Human dietary exposure to contaminants in grains}

Using data from the UK National Diet and Nutrition Survey, the relative (\%) contribution of grain (cereal) and grain products to energy and macronutrient intakes can be viewed as considerably greater than for meat, milk, or fruit and vegetables (see Table 2). For example, cereal and cereal products contribute $2-3.5 \%$ more to total energy intakes in the total population than each of the other food groups listed. Hence, while grain-based foods can contain low levels of contaminants because they are consumed in significant quantities by large sections of the population, they can make significant contributions to dietary contaminant exposure assessments. This contributions by grains is reflected in recent EFSA Opinions for metals such as cadmium (EFSA, 2012) and arsenic (EFSA 2009, 2014). To refine risk assessments and ensure accurate estimates of contaminant intake there has been calls by EFSA for occurrence data on the presence of acrylamide, mycotoxins and heavy metals (EFSA 2018). Further refinements of mycotoxin intake may also need to account the possibility also exists for carry-over of contaminants in grains fed to animals as part of 'rations' or concentrates' to foods of animal original which are then consumed by humanse.g. the mycotoxin, aflatoxin B1 in dairy cattle feed which can be metabolised to aflatoxin M1 and subsequently occur in milk (Veldman et al. 1992). For the assessment of contaminants in heavy metals, difficultly also arises from the fact that bioaccumulation of heavy metals differs between plant species and depends on concentrations of metals present in the soil (Khan et al. 2015). Overall, in Europe, exposure to contaminants in wholegrains remain low but there is a need for continued monitoring, particularly in areas of increased risk such as developing countries (Thielecke \& Nugent 2018). This is true not only for grains but all foods. 
Strategies to mitigate risk of contaminants to human health

There are a number of steps in the food chain which can influence exposure to contaminants in grains. Considered here is the influence of regulators, farming or production practices, processing and manufacturing, as well as the actions of consumers.

\section{Role of farming and production sectors}

Farming and production practices can directly influence the presence or absence of contaminants within grains, with different influences for each type of contaminant. For example, the temperature, grain moisture content and relative humidity of grain storage conditions are critical factors favouring fungal growth and subsequent mycotoxin production, as is grain damage from pests or birds in the field (FAO; WHO 2003) Whereas, the presence and concentration of heavy metals in grains is directly influenced by those in the soil(. For the process contaminant acrylamide, the presence of the amino acid asparagine within the grain is a critical component (Curtis \& Halford 2016). Hence, multiple strategies are needed to ensure the presence of contaminants are minimised within the final grain product. Examples include following best practice guidelines for storage conditions, minimising insect and bird damage, following appropriate crop rotation, appropriate fertilisation and/or crop selection and milling (for review see Thielecke \& Nugent 2018).

\section{Does post-harvest treatment work?}

There are some suggested methods for treating or removing contaminants in grains (e.g. use of gases such as ammonia, chlorine dioxice, sulphur dioxide or ozone to treat mycotoxin-contaminated grains). However, as yet such approaches are restricted in their reach and efficacy and each with limitations for use and currently prevention remains a more efficient method than treatment (Karlovsky et al. 2016).

\section{Do grains themselves provide protection?}

There is some evidence that the nutritional composition of wholegrains may in itself provide protection. Wholegrains are more nutrient dense than refined grains as the bran and germ present in wholegrains contains much of the fibre and micronutrients (Papanikolaou \& Fulgoni 2017; Robinson 
\& Chambers 2018; Thielecke \& Nugent 2018). Refining removes the bran and germ, and up to $80 \%$ of minerals, such as iron and zinc, leaving only the endosperm (which contains mostly carbohydrate, protein and small amounts of some B vitamins and minerals). There is some evidence to suggest that the combination of nutrients present in wholegrains can help mitigate against the negative effects of contaminants with scope for further research in this area (Thielecke \& Nugent 2018). For example, the presence of vitamins, carotenoids and antioxidants (e.g. ferulic aicd in wholegrain wheat) has the potential to reduce the impact of mycotoxins by protecting cell membranes from mycotoxin-induced damage (Atroshi et al. 2002; Gross-Steinmeyer \& Eaton 2012).. Another potential strategies to mitigate the effects of mycotoxins includes the binding of probiotic micro-organisms to mycotoxins to decrease their gastrointestinal absorption (Thielecke \& Nugent 2018). This has been described in milk (Wochner et al. 2018) and there is some limited evidence for kefir grains (Taheur et al. 2017), corn, sorghum and rice (Kim et al. 2017). Further research is needed to explore the potential of probiotics to influence the adsorption of mycotoxins.

For toxic metals, the primary line of defence is at the site of absorption. As with essential minerals, toxic metals must bind with transporters in the small intestines prior to absorption, with empirical data suggesting optimal levels of nutrients such as magnesium, zinc, selenium, calcium, iron and dietary fibre may reduce toxicity (Elsenhans et al. 1991). This may imply that if consumption of minerals is optimal, it might mitigate against the toxicity of heavy metals (Thielecke \& Nugent 2018). There is some evidence from cellular and animal studies for a protective effect of selenium, magnesium, calcium, zinc, iron and dietary fibres in the absorption of heavy metals but more research is needed to understand the role of these bioactives when present naturally within a grain matrix (Thielecke \& Nugent, 2018). Evidence for supporting mechanisms of action is limited but for cadmium absorption at least may involve the metal binding proteins metallothioneine and/or glutathione (Grosicki et al. 2015; Shabb et al. 2017). Unsurprisingly, evidence from human trials is limited due to ethical reasons. However, there is epidemiological evidence suggesting that iron deficiency can lead to increases in lead absorption (Kordas 2010; Wright et al. 2003) and an inverse relationship has been noted between calcium deficiency and blood lead levels (Mahaffey et al. 1986). It has been suggested that people eating a diet deficient in micronutrients will be predisposed to toxicity from nonessential (heavy) metals (Peraz et al. 1998). So, while there is limited evidence to suggest that the presence of micronutrients in wholegrains may help mitigate the risk of heavy metal contamination, there is comfort in the lack of evidence to suggest that consuming wholegrains increases any such risk (Thielecke \& Nugent 2018). 
Role of the regulator

Regulatory agencies both globally, regionally and nationally have clear strategies in place to ensure that levels of contaminants in food or feed are as low as reasonably possible through Good Agricultural Practice and Good Manufacturing Practice (EC 1993; FAO/WHO 1995), codes of practice and risk assessment and risk management strategies. Since many contaminants are naturally occurring it would be impossible to impose a total ban on their presence; hence most Regulatory Agencies have developed, and subsequently monitor and enforce, maximum acceptable levels of contaminants in foods that are scientifically based and technologically practical (e.g. for mycotoxins) (EC 2006). Within Europe, EFSA provides scientific advice and guidance on suitable maximal levels of contaminants but it is the responsibility of individual Member States to ensure compliance, with responsibility for imported foodstuffs resting with the country of origin. The US Food and Drug Administration and Food Inspection Agency in Canada hold similar roles to EFSA in the EU. While are there some differences in approaches and regulatory limits applied between jurisdictions, the public can be reassured by the rigorous monitoring and enforcement strategies that are in place which ensure the highest food safety standards and protection to public health.

What about the consumer?

, There are several way consumers can reduce the potential risk to health of contaminants in wholegrain foods. First by following basic good hygiene and correct food storage practices. For example, adhering to 'use by' dates to avoid consumption of bread on which fungal moulds have grown, or avoiding over-toasting bread or wholegrain products to minimise exposure to acrylamide. Such steps are of course more difficult when individuals or populations are experiencing food poverty and/or food insecurity and especially so where presence of contaminants (particularly mycotoxins) is less routinely monitored than in Western Societies. Whilst opting for processed foods might protect as contaminants tend to be lower in these foods, this is not always the case (e.g. cadmium levels are higher in refined than unrefined flour) (Thielecke \& Nugent 2018) and it is well described that processed foods can be higher in less desirable nutrients from a public health perspective (e.g. salt, sugar and/or fat). and wholegrains are recommended as part of a healthy, balanced diet. Rinsing and cooking can reduce arsenic levels in rice, with cooking in excess water suggested as helpful at reducing arsenic content (Raab et al. 2009). However, this can also result in losses of nutrients such as iron, folate, niacin and thiamine, but more so for polished and parboiled varieties than for wholegrain brown rice (Gray et al. 2016). Hence, consumers may wish to consider both the variety of rice and cooking methods if attempting to reduce arsenic concentrations in rice (BNF 2018). 
Currently, consumers are advised to consume wholegrains as part of food-based dietary guidelines. For example, the UK Eatwell Guide states 'Choose wholegrain or higher fibre versions (of starchy carbohydrates)' (PHE 2016). Support for such a recommendation arises from an ever growing number of scientific reports suggesting wholegrains in place of refined grains improves the nutritional quality of carbohydrate intake (SACN 2015; Robinson \& Chambers 2018), with wholegrains also recommended as part of sustainable, healthy diets (Willett et al. 2019). Thus, consumers will benefit most by choosing a healthy balanced diet rich in whole grains rather than avoiding grain intake.

\section{Conclusion}

Globally, grains are an important dietary source of energy and many nutrients, particularly carbohydrate. They can be also a noteworthy source of dietary contaminants, particularly mycotoxins and heavy metals. However, there are number of important assurances which ensure a place of wholegrains in our diets. Nutritionally, diets rich in wholegrains have been associated with a more nutrient dense diet than those rich in refined grains and with reduced risk of many chronic diseases. They are also promoted as a sustainable food choice. The importance of ongoing activities by Regulatory Authorities in providing guidance and assessing risk cannot be overstated in ensuring the safety of our food supply. In addition, we suggest that based on the observational and preclinical evidence described here, there may be potentially protective effects of the phytonutrients in grains against contaminants (e.g. mycotoxins and heavy metals) which merit further research. The consumer is best protected by eating healthy balanced diet, rich in nutrient dense foods, including wholegrain options. 


\section{References}

Albertson AM, Reicks M, Joshi N et al. (2016) Whole grain consumption trends and associations with body weight measures in the United States: results from the cross sectional National Health and Nutrition Examination Survey 2001-2012. Nutrition Journal 15: 8.

Alshannaq A, Yu JH (2017) Occurrence, Toxicity, and Analysis of Major Mycotoxins in Food. International Journal of Environmental Research Public Health 14(6) 632.

Andrade VM, Aschner M, Dos Santos APM (2017) Neurotoxicity of Metal Mixtures. Advances in Neurobiology 18: 227-265.

Atroshi F, Rizzo A, Westermarck T et al. (2002) Antioxidant nutrients and mycotoxins. Toxicology 180(2): 151-67.

Aune D, Chan DS, Lau R et al. (2011) Dietary fibre, whole grains, and risk of colorectal cancer: systematic review and dose-response meta-analysis of prospective studies. British Medical Journal 34: d6617.

Battilani P, Toscano P, Van der Fels-Klerx et al. (2016) Aflatoxin B1 contamination in maize in Europe increases due to climate change. Scientific Reports 6: 24328.38-40.

Bellisle F, Hébel P, Colin J et al. (2014) Consumption of whole grains in French children, adolescents and adults British Journal of Nutrition 112 (10): 1674-1684.

Benisi-Kohansal S, Saneei P, Salehi-Marzijarani M et al, (2016) Whole-Grain Intake and Mortality from All Causes, Cardiovascular Disease, and Cancer: A Systematic Review and Dose-Response MetaAnalysis of Prospective Cohort Studies. Advances in Nutrition. 7(6): 1052-65.

Bennett J, Bentley R (1999) Pride and Prejudice: The Story of Ergot. Perspectives in Biology and Medicine 42(3): 333-355.

BDA (British Dietetic Association) 2016 Wholegrains. Available at www.bda.uk.com/foodfacts/wholegrains.pdf (accessed 28th February 2019)

BNF (British Nutrition Foundation) (2017) Arsenic in rice - is it a cause for concern? Available at: www.nutrition.org.uk/nutritioninthenews/headlines/arsenicinrice.html (accessed $28^{\text {th }}$ February 2019).

CPW (Cereal Partners Worldwide) (2017) Consumers confused about how much is enough when it comes to whole grain in their diets. Available at: www.nestle.com/assetlibrary/documents/media/news-feed/cpw-whoe-grain-press-release-nov-2017.pdf (accessed 28th 
February 2019).Curtis TY \& Halford NG (2016) Reducing the acrylamide-forming potential of wheat. Food Energy and Security 5, 153-164.

Freire F.D.C.O., da Rocha M.E.B. (2016) Impact of Mycotoxins on Human Health. In: Mérillon JM., Ramawat K. (eds) Fungal Metabolites. Reference Series in Phytochemistry. Springer, Cham.

EC (European Commission) Arsenic. Available at: https://ec.europa.eu/food/safety/chemical safety/contaminants/catalogue/arsenic en (accessed 28th March 2019)

EC (European Commission) No 315/93 Laying down Community procedures for contaminants in food, in Council Regulation. 1993: Official Journal of the European Communities, Belgium.

EC (European Commission) (2017) EC regulation 2017/2158 establishing mitigation measures and benchmark levels for the reduction of the presence of acrylamide in food, in Council Regulation. Official Journal of the European Union.

EC (European Commission) (2006). EC Regulation 1881/2006 setting maximum levels for certain contaminants in foodstuffs and amendments. Available at: https://eurlex.europa.eu/eli/reg/2006/1881/oj/eng (accessed $28^{\text {th }}$ February 2019). EFSA (European Food Safety Authority) (2018) Call for continuous collection of chemical contaminants occurrence data in food and feed. Available at: https://www.efsa.europa.eu/en/consultations/call/180307 (accessed $28^{\text {th }}$ March 2019)EFSA (European Food Safety Authority) (2016) The 2016 European Union report on pesticide residues in food. EFSA Journal, 16(7).

EFSA (European Food Safety Authority) (2016) Contaminants in food and feed. Available at: www.efsa.europa.eu/en/topics/topic/contaminants-food-and-feed (accessed $28^{\text {th }}$ February 2019). EFSA (European Food Safety Authority) (2014) Dietary exposure to inorganic arsenic in the European population. EFSA Journal 12(3): 3597.

EFSA (European Food Safety Authority) (2012) Cadmium dietary exposure in the European population. Available at: https://efsa.onlinelibrary.wiley.com/doi/epdf/10.2903/i.efsa.2012.2551 (accessed $28^{\text {th }}$ February 2019).

EFSA (European Food Safety Authority) (2009) Scientific Opinion on Arsenic in Food. EFSA Journal 7(10): 1351. 
Elsenhans BS, Schumann K, Forth W (1991) Toxic metals: interactions with essential metals. In Nutrition, Toxicity, and Cancer (ed Rowland, IR) p. 223-258. CRC Press: New York.

EUFIC (European Food Information Council) (2015) Wholegrains. Available at: https://www.eufic.org/en/whats-in-food/article/whole-grains-updated-2015 (accessed 28 February 2019).

FAO (Food and Agriculture Organization) World Food Situation. Available at: www.fao.org/3/CA2726EN/ca2726en.pdf (accessed 28 February 2019)

FAO (Food and Agriculture Organization) Staple foods: What do people eat? 13.07.2018]; Available at: www.fao.org/docrep/u8480e/u8480e07.htm (accessed 28 February 2019)

FAO/WHO (Food and Agriculture Organization/World Health Organization) (2003) Code of Practice for the Prevention and deduction of mycotoxin Contamination in Cereals. Codex Alimentarius: Rome, Italy.

FAO/WHO (Food and Agriculture Organization/World Health Organization) (1995) Codex General Standard for Contaminants and Toxins in Food and Feed. Codex Alimentarius: Rome, Italy. FDA (Food and Drug Administration) (1999) U.S. Health Claim Notification for Whole Grain Foods. Available at: www.fda.gov/food/labelingnutrition/ucm073639.htm (accessed 28 February 2019)

Global Burden of Disease Study (GBD Study) (2018), Global, regional, and national comparative risk assessment of 84 behavioural, environmental and occupational, and metabolic risks or clusters of risks, 1990-2016: a systematic analysis for the Global Burden of Disease Study 2017. Lancet, 392: $\underline{1923-94}$

Gray PJ, Conklin SD, Todorov TI et al. (2016) Cooking rice in excess water reduces both arsenic and enriched vitamins in the cooked grain. Food Additives Contaminants Part A Chemical Analysis Control Exposure Risk Assessment 33(1): 78-85.

Greenerchoices (2014) Report: Analysis of Arsenic in Rice and Other Grains. Executive Summary. Consumer reports 2014 Available at: http://greenerchoices.org/2014/11/01/test-results-arsenicrice-grains/ (accessed $28^{\text {th }}$ February 2019).

Greve C, Ness RI (2014) The Evolution of the Whole Grain Partnership in Denmark. Available at: https://research.cbs.dk/en/publications/the-evolution-of-the-whole-grain-partnership-in-denmark (accessed $28^{\text {th }}$ February 2019). 
Grosicki A, Malagocki P, Kycok A et al. (2015) Magnesium supplements affect selected cadmium toxic actions and uptake of repeated doses of cadmium. 59(4): 541.

Gross-Steinmeyer K, Eaton DL (2012) Dietary modulation of the biotransformation and genotoxicity of aflatoxin B(1). Toxicology 299(2-3): 69-79.

IAACC (International, Association of Cereal Chemists). Whole Grains. Available at: www.aaccnet.org/initiatives/definitions/Pages/WholeGrain.aspx (accessed 28 February 2019) IARC (International Agency for Research on Cancer) (1994) Some Industrial Chemicals, International Agency for Research on Cancer : Lyon, France. p. 435.

Kärkkäinen O, Lankinen MA, Vitale M et al. (2018) Diets rich in whole grains increase betainized compounds associated with glucose metabolism American Journal of Clinical Nutrition 108 (5), 971 979.

Karlovsky P, Suman M, Berthiller F et al. (2016) Impact of food processing and detoxification treatments on mycotoxin contamination. Mycotoxin Research 32(4): 179-2

Khan A, Khan S, Khan MA et al. (2015)

The uptake and bioaccumulation of heavy metals by food plants, their effects on plants nutrients, and associated health risk: a review. Environmental Science Pollution Research International 22(18):13772-99.

Kim S, Lee H, Lee S et al. (2017) Invited review: Microbe-mediated aflatoxin decontamination of dairy products and feeds. Journal of Dairy Science 100(2): 871-880.

Kordas K (2010) Iron, Lead, and Children's Behavior and Cognition. Annual Reviews Nutrition 30: 12348.

Kosek-Hoehne, KPB, Śliwa A (2017) Heavy metals - a silent threat to health. Journal of Education, Health and Sport 7(1): 121-132.

Kuzenesof S, Brownlee IA, Moore C et al. (2012) WHOLEheart study participant acceptance of whole grain foods. Appetite 59, 187-93.

Lee HJ, Ryu D (2017) Worldwide Occurrence of Mycotoxins in Cereals and Cereal-Derived Food Products: Public Health Perspectives of Their Co-occurrence. Journal of Agricultural Food Chemistry 65(33): 7034-7051. 
Mahaffey KR, Gartside PS, Glueck CJ (1986) Blood lead levels and dietary calcium intake in 1- to 11year-old children: the Second National Health and Nutrition Examination Survey, 1976 to 1980.

Pediatrics, 78(2): 257-62.

Marvin, HJP. (2012) EMTOX: Climate change impacts on natural toxins in marine and primary plant production system in north west Europe by 2040. Food Additives \& Contaminants: Part A, 29(10): 1501-1501.

McMahon E, Dean M, Woodside JV et al. (2013) Whole grains and health attitudes to whole grains against a prevailing background of increased marketing and promotion. Public Health Nutrition 16:

743-51.

Moretti A, Logrieco AF, Susca A (2017) Mycotoxins: An Underhand Food Problem. Methods in Molecular Biology 1542: 3-12.

Moretti A, Pascale M, Logrieco AF (2019) Mycotoxins risk under a climate change scenario in Europe. Trends in Food Science and Technology 84:

Ness RI (2014) Whole grain intake sets new record (press release). Available at: www.fuldkorn.dk/media/162235/PRM-Whole-grain-intake-sets-new-record.pdf (accessed $28^{\text {th }}$ February 2019).

Papanikolaou Y, Fulgoni VL. (2017) Grain Foods Are Contributors of Nutrient Density for American Adults and Help Close Nutrient Recommendation Gaps: Data from the National Health and Nutrition Examination Survey, 2009-2012. Nutrients 9(8): 873.

Peraza MA, Ayala-Fierro F, Barber DS et al. (1998) Effects of micronutrients on metal toxicity. Environmental Health Perspectives 106 (1): 203-16.

PHE (Public Health England) (2018) NDNS: Results from Years 7 and 8 combined. Available at https://www.gov.uk/government/statistics/ndns-results-from-years-7-and-8-combined. (accessed $28^{\text {th }}$ March 2019).

PHE (Public Health England) (2016) The Eatwell Guide. Available at: www.gov.uk/government/news/new-eatwell-guide-illustrates-a-healthy-balanced-diet (accessed $28^{\text {th }}$ February 2019).

Raab AF, Feldmann J, Meharg AA (2009) Levels of arsenic in rice: the effects of cooking, Food Standards Agency: London.

Reyolds A, Mann J, Cummings C et al. (2019) Carbohydrate quality and human health: a series of systematic reviews and meta-analyses. The Lancet 393: 434-45. 
Robinson E, Chambers L (2018) The challenge of increasing whole grain intake in the UK. Nutrition Bulletin 43: 135-46.

Ross, A.B., et al., Perspective: A Definition for Whole-Grain Food Products-Recommendations from the Healthgrain Forum. Adv Nutr, 2017. 8(4): p. 525-531

SACN (Scientific Advisory Committee on Nutrition) (2015) Carbohydrates and heath. Available at: www.gov.uk/government/publications/sacn-carbohydrates-and-health-report (accessed $28^{\text {th }}$ February 2019)

Scudamore KA, Patel S (2009) Fusarium mycotoxins in milling streams from the commercial milling of maize imported to the UK, and relevance to current legislation. Food Additives Contaminants Part A Chemical Analysis Control Exposure Risk Assessment 26(5): 744-53.

Seal CJ, Nugent AP, Tee ES et al. et al. (2016) Whole-grain dietary recommendations: the need for a unified global approach. British Journal of Nutrition 115(11): 2031-8.

Seal CJ, Thielecke FT (2018) Health Benefits and Recommendations for Daily Whole Grain Intake. Cereal Foods World 63(3):103-106).

Sette S, D'Addezio L, Piccinelli R et al. (2017) Intakes of whole grain in an Italian sample of children, adolescents and adults. European Journal of Nutrition 56(2): 521-533.

Shabb JB, Muhonen WW, Mehus AA (2017) Quantitation of Human Metallothionein Isoforms in Cells, Tissues, and Cerebrospinal Fluid by Mass Spectrometry. Methods Enzymology 586: 413-431. Taheur FB, Fedhila K, Chaieb K et al. (2017) Adsorption of aflatoxin B1, zearalenone and ochratoxin A by microorganisms isolated from Kefir grains. International Journal Food Microbiology 251: 1-7. Tchounwou PB, Yedjou CB, Patollla AK et al. (2012) Heavy metals toxicity and the environment. Molecular Clinical Environmental Toxicology 101, 133-164

Thielecke F, Nugent AP (2018) Contaminants in Grain - a major risk for whole grain safety? Nutrients 10: 1213.

Thorning TK, Bertram HC, Bonjour JP et al. (2017) Whole dairy matrix or single nutrients in assessment of health effects: current evidence and knowledge gaps. American Journal of Clinical Nutrition 105, 1033-1045.

Van der Fels-Klerx, HJ, van Asselt ED, Madsen MS et al. (2013) Impact of climate change effects on contamination of cereal grains with deoxynivalenol. PLoS One, 8(9): e73602. 
van der Kamp JW, Poutanen K, Seal CJ et al. (2014) The HEALTHGRAIN definition of 'whole grain'. Food Nutrition Research 58, 22100

Veldman AM, Mejis JAC, Borggreve GJ et al. (1992) Carry-over of aflatoxin from cows' food to milk. Animal Science 55(2): 163-168.

Whole Grain Council (2005) Whole grain stamp. Available at: https://wholegrainscouncil.org/wholegrain-stamp. (accessed $28^{\text {th }}$ February 2019).

Willett W, Rockstrom J, Loken B et al. (2019) Food in the Anthropocene: the EAT-Lancet Commission on healthy diets from sustainable food systems. The Lancety 393: 447-92.

Wochner KF, Becker-Algeri TA, Colla E et al. (2018) The action of probiotic microorganisms on chemical contaminants in milk. Critical Reviews in Microbiology 44(1): 112-123.

Wright RO, Tsaih SW, Schwartz J et al. (2003) Association between iron deficiency and blood lead level in a longitudinal analysis of children followed in an urban primary care clinic. The Journal of Pediatrics 142(1): 9-14.

Wu H, Flint AG, Qi Q et al. (2015) Association between dietary whole grain intake and risk of mortality: two large prospective studies in US men and women. JAMA International Medicine 175(3): 373-84.

Ye EQ, Chacko SA, Chou EL et al. (2012) Greater whole-grain intake is associated with lower risk of type 2 diabetes, cardiovascular disease, and weight gain. Journal of Nutrition 142(7): 1304-13.

Zong G, Gao A, Hu FB et al. (2016) Whole Grain Intake and Mortality From All Causes, Cardiovascular Disease, and Cancer: A Meta-Analysis of Prospective Cohort Studies. Circulation 133(24), 2370-80. 
Table 1: Summary of the main mycotoxins in grains, their sources and effects on human health as modified from Thielecke \& Nugent 2018

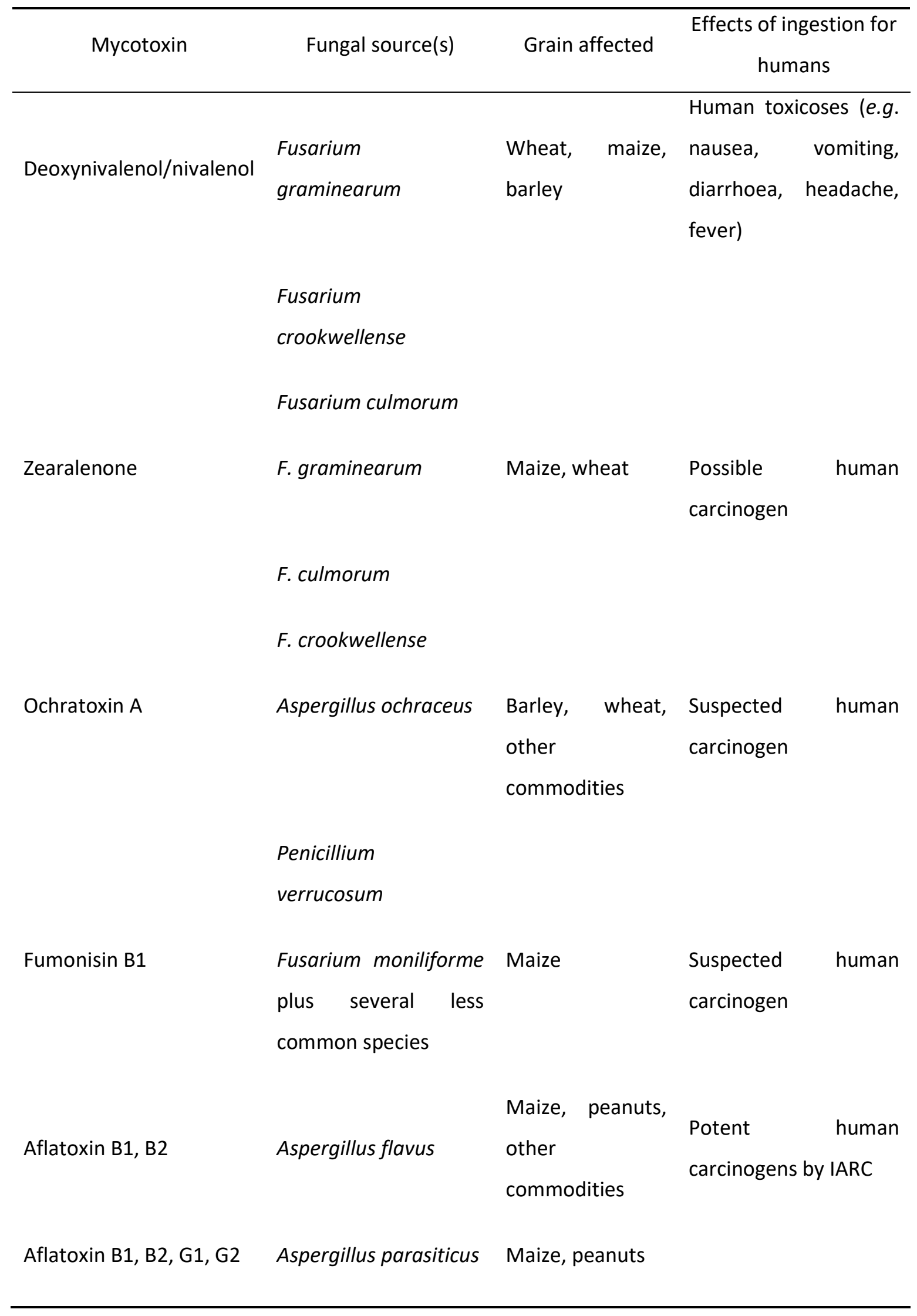


Table 1: Percent contribution of key commodities to energy, macronutrient and fibre intake of UK adults aged 19-64 years. Data from National Diet and Nutrition Survey years 7 and 8, 2014/2015 and 2015/2016. (Public Health England, 2018)

\begin{tabular}{cccccc}
\hline & Energy (\%) & Protein (\%) & Fat (\%) & $\begin{array}{c}\text { Carbohydrate } \\
\text { (\%) }\end{array}$ & Fibre (\%) \\
\hline $\begin{array}{c}\text { All Cereal and } \\
\text { cereal products } \\
\begin{array}{c}\text { Meat and meat } \\
\text { products }\end{array}\end{array}$ & 32 & 23 & 21 & 46 & 38 \\
$\begin{array}{c}\text { Milk and milk } \\
\text { products }\end{array}$ & 9 & 37 & 24 & 6 & 12 \\
$\begin{array}{c}\text { Fruit, vegetables } \\
\text { and salad }\end{array}$ & 9 & 13 & 12 & 5 & 1 \\
vegetables & 7 & 6 & 11 & 28 \\
\hline
\end{tabular}

